\title{
How Subsidence Affects Clinical and Radiological Outcomes after Stand-Alone Anterior Cervical Discectomy and Fusion on Patients with Degenerative Cenvical Disease? A Long-Term Follow-Up Study
}

\author{
In-Chul Yang, Moon-Soo Han, Gwang-Jun Lee, Seul-Kee Lee, Bong Ju Moon, Jung-Kil Lee \\ Department of Neurosurgery, Chonnam National University Hospital, Chonnam National University College of Medicine, \\ Gwangju, Republic of Korea
}

Corresponding author:

Jung-Kil Lee

Department of Neurosurgery,

Chonnam National University

Hospital, Chonnam National

University College of Medicine,

42, Jebong-ro, Dong-gu, Gwangju

61469 , Republic of Korea

Tel: +82-62-220-6602

Fax: +82-62-224-9865

E-mail: jkl@chonnam.ac.kr

Received: June 29, 2021

Revised: July 29, 2021

Accepted: August 16, 2021

\begin{abstract}
Objective: We aimed to examine the long-term radiological and clinical outcomes after stand-alone anterior cervical discectomy and fusion (ACDF).

Methods: In total, we enrolled 20 patients and 31 treated segments with degenerative cervical disease that underwent stand-alone ACDF with $\geq 60$ months of follow-up. Segmental angle (SA), cervical sagittal alignment (CSA), subsidence, and fusion were evaluated. A visual analogue scale (VAS) and the neck disability index (NDI) were applied pre- and post-operatively and at the last follow-up.

Results: Subsidence occurred in 9 (45\%) patients and 15 segments (48.4\%) at the last follow-up. The mean VAS and NDI scores had improved in both groups with and without subsidence. The mean SA at the last follow-up had significantly increased to $2.3^{\circ} \pm 8.5^{\circ}$ in the subsidence group and to $1.7^{\circ} \pm$ $5.2^{\circ}$ degree in the non-subsidence group compared to the post-operative $S A(p<0.001)$. The overall mean CSA at the last follow-up significantly increased overtime in both groups from the postoperative CSA ( $p=0.003$ ). The fusion rate was $86.7 \%$ in the subsidence group and $81.3 \%$ in non-subsidence group. However, the difference in SA, CSA and fusion rates between the two groups were not statistically significant $(p=0.119,0.98$, and 0.682 , respectively).

Conclusion: As a result of a long-term follow-up study after stand-alone ACDF, subsidence occurs to some extent. Still, it does not appear to significantly impact radiological and clinical outcomes if the clinician performs sufficient decompression of foramen during surgery. Subsidence seems to have a positive influence on the fusion rate.
\end{abstract}

Key Words: Cervical vertebrae; Diskectomy; Follow-up studies; Spinal fusion

\section{INTRODUCTION}

Anterior cenvical discectomy and fusion (ACDF) with plate fixation has been recommended for degenerative cervical disease of two or more levels, with instability and kyphosis ${ }^{15,25}$. However, adding a cervical plate is associated with plate-related complications such as material failure, dysphagia, and adjacent segment degeneration $(A S D)^{13,17}$. For these reasons, recent studies suggest that stand-alone ACDF without plate fixation is a safe and effective treatment option for cenvical degenerative disease ${ }^{16,18)}$. These reports, however, had a follow-up period of two years or fewer. Additionally, the most important issue of stand-alone ACDF is cage subsidence, which can cause kyphotic segmental change or kyphotic recurrence. As per some studies, cage subsidence is reported to have occurred in $19.1 \%$ to $62.5 \%$ of the patients who underwent stand-alone $\mathrm{ACDF}^{1,2,5,22,23)}$. Some studies reported that stand-alone ACDF is not satisfactory with worse radiologic outcomes than ACDF with plate fixation ${ }^{10,11)}$. Nevertheless, cage subsidence and segmental kyphotic change were not significantly associated with clinical outcomes in a short follow-up period ${ }^{7,8)}$.

The objective of this study was to evaluate the feasibility of standalone ACDF using polyether ether ketone (PEEK) cages without plate fixation by analyzing the long-term clinical and radiological outcomes.

\section{MATERIALS AND METHODS}

\section{Patient Population and Study Design}

We conducted a retrospective review of 304 patients with degenerative cenvical disease who underwent $A C D F$ with or without plate fixation between 2005 and October 2015 at our institution. The inclusion criteria were as follows: (1) patients with signs and symptoms of cervical radiculopathy or cervical spondylotic myelopathy who were unresponsive to medical treatment, (2) patients treated with one-, two-, or multiple level stand-alone ACDF, and (3) clinical and radiologic follow-up of $\geq 60$ months after surgery. The exclusion criteria were as follows: (1) patients who underwent previous cervical spine surgery, (2) patients with other cenvical disease including infe- 
ction or tumor, and (3) patients with $<60$ months clinical or radiological follow-up after surgery.

In total, we enrolled 20 study patients with degenerative cervical disease who underwent stand-alone ACDF with $\geq 60$ months followup. To identify the patients' clinical characteristics, clinical data at the time of treatment, including age, sex, presenting symptoms, bone mineral density, level of surgery, plain radiographs, computed tomography (CT) scans, and magnetic resonance imaging scans of the cervical spine were collected.

\section{Surgical Technique}

General anesthesia was used in all patients. Standard Smith-Robinson method was performed to expose the involved segment. The proper PEEK cage was selected (Solis ${ }^{\circledR}$ cage, Stryker Spine, Allendale, NJ, USA; Cornerstone cage, Medtronic, Memphis, TN, USA). The cages were packed with a demineralized bone matrix (SureFuse ${ }^{T M}$; Hansbiomed Corp., Seoul, Korea), mixed with autologous bone chips, and inserted into the disc space. The operation was completed without anterior plating.

\section{Radiological and Clinical Evaluation}

CT was performed at 6 months after surgery and once a year thereafter to evaluate fusion. Fusion was defined as less than 2-mm motion between the spinous processes on flexion-extension lateral radiographs, less than $50 \%$ of radiolucency covering the implant's outer surface, and the presence of continuous bridging trabeculae at the graft on simple lateral radiographs or CT scans ${ }^{21)}$. The cervical sagittal alignment (CSA), segmental angle (SA), and subsidence were measured using lateral plain radiographs. The overall CSA was measured according to the Cobb's angle (CA) between the lower endplate of C2 and the lower endplate of C7. SA was also measured

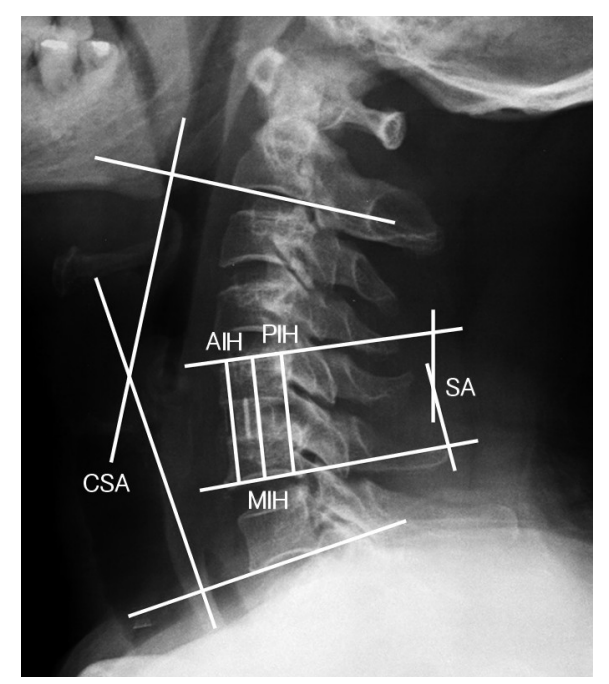

Fig. 1. Cervical sagittal alignment (CSA), segmental angle (SA), anterior intervertebral height $(A H)$, middle intervertebral height $(M H)$, and posterior intervertebral height $(\mathrm{PIH})$ on lateral radiographs of cervical spine. using the $C A$, the angle between the superior endplate of the upper adjacent vertebra, and the inferior endplate of the lower adjacent vertebra at the operated disc level. Kyphosis was noted as a positive value, while lordosis was noted as a negative value. Subsidence was defined as a decrease in the total intervertebral height (TIH) between the two adjacent vertebral bodies on comparing post-operative lateral plain radiographs. The $\mathrm{TIH}$ was measured at three points: anterior, middle, and posterior points of the superior endplate of the upper adjacent vertebra and the inferior endplate of the lower adjacent vertebra at the operated disc level (Fig. 1). Based on serial $\mathrm{TIH}$ analysis, subsidence was defined if the TIH decreased more than $3.0 \mathrm{~mm}$ at any three points than the $\mathrm{TIH}$ taken post-operatively $y^{5,6,10)}$.

To evaluate pain in the neck and arms, a visual analogue scale (VAS) was applied pre- and post-operatively. Additionally, the neck disability index (NDI) questionnaire was administered pre- and postoperatively and at the last follow-up.

\section{Statistical Analysis}

The data of this study were entered into SPSS version 25.0 (SPSS Inc., Chicago, IL USA), and $\chi^{2}$ test was used to compare the qualitative data between the groups. The one-way ANOVA test was used for quantitative data. Paired samples $t$-test was used to evaluate the results before and after surgery. The independent $t$-test and Mann-Whitney $U$ test for parametric or nonparametric variables were used for analyzing relationships between clinical and radiologic results and subsidence. Quantitative data were presented as the mean and standard deviation and qualitative data were presented as frequency or percentage. A p-value of less than 0.05 was considered as a significant relationship.

\section{RESULTS}

\section{Patient Characteristics}

A total of 20 patients with a total of 31 treated segments were included in this study. The mean age of the patients at the time of stand-alone ACDF was 59 years (range, 30-74 years). There were $16(80 \%)$ male patients and $4(20 \%)$ female patients. The number of stand-alone ACDF procedures at one-, two-, and three-segments was reported in $10(50 \%), 9(45 \%)$, and $1(5 \%)$ patient, respectively. Stand-alone ACDF was commonly performed at the C5-6 level (14 segments, 45.2\%), followed by C6-7 level (9 segments, 29.0\%), C4-5 level (5 segments, 16.1\%), and C3-4 level (3 segments, 9.7\%). The overall mean follow-up period after surgery was 77 months (range, 60-150 months). The clinical characteristics of the enrolled patients are summarized in Table 1.

\section{Radiological Outcomes}

Fusion was achieved in 26 segments (83.9\%) at the last follow-up. Subsidence occurred in 9 (45\%) patients and 15 segments (48.4\%) at the last follow-up. The patients were divided into the subsidence 
group and non-subsidence group. In the subsidence group, there were 8 male and 1 female patient with a mean age of 55.3 years

Table 1. Clinical characteristics of patients

\begin{tabular}{lc}
\hline \multicolumn{1}{c}{ Variables } & Value $(\mathrm{n}=20)$ \\
\hline Mean age (years) & $59(30-74)$ \\
Sex & $16(80.0)$ \\
Male & $4(20.0)$ \\
Female & $-1.5 \pm 0.9$ \\
BMD & \\
Stand-alone ACDF & $10(50.0)$ \\
1 segment & $9(45.0)$ \\
2 segments & $1(5.0)$ \\
3 segments & 31 \\
Level of segments & $3(9.7)$ \\
C3-4 & $5(16.1)$ \\
C4-5 & $14(45.2)$ \\
C5-6 & $9(29.0)$ \\
C6-7 & $77(60-150)$ \\
Mean follow-up period (months)
\end{tabular}

The data is presented as mean (range), number (\%), or mean \pm standard deviation.

ACDF: anterior cervical discectomy and fusion; BMD: bone mineral density. (range, 31-74 years). In the non-subsidence group, 8 male and 3 female patients with a mean age of 47.9 (range, 30-71 years). The mean follow-up duration was 68.5 months (range, 60-96 months) and 85.8 months (range, 60-150 months) in the subsidence group and non-subsidence group, respectively (Table 2). The decrease in intervertebral height mainly occurred on the anterior, middle, and posterior portions at the same time. Anterior-only, middleonly subsidence, and combined anterior and middle subsidence occurred; however, posterior-only subsidence was not observed. The mean anterior intervertebral height (AH), middle intervertebral height $(\mathrm{MIH})$, and posterior intervertebral height $(\mathrm{PIH})$ in the subsidence group decreased by $6.1 \pm 2.5,6.0 \pm 2.8$, and $4.6 \pm 3.1 \mathrm{~mm}$, respectively, and in non-subsidence group, they decreased by $1.5 \pm 1.3$, $1.5 \pm 1.2$, and $1.2 \pm 1.4 \mathrm{~mm}$, respectively, from the values recorded immediately after surgery to those recorded at the last follow-up. Although the $\mathrm{AlH}, \mathrm{MIH}$, and $\mathrm{PIH}$ significantly decreased from after surgery to the last follow-up in both groups, $\mathrm{THH}$ significantly decreased more over time in the subsidence group than in the non-subsidence group $(p<0.0001)$. The $\mathrm{AlH}, \mathrm{MHH}$, and $\mathrm{PIH}$ had mostly changed within one-year after surgery (Fig. 2). The overall mean $\mathrm{SA}$ of the last follow-up significantly increased by $2.3 \pm 8.5$ degree at the last follow-up in subsidence group and $1.7 \pm 5.2$ degrees in the non-subsidence group compared to the values postoperatively $(p<0.001)$, but there was no significant difference between the two groups $(p=0.119)$. The overall mean CSA at the last follow-up significantly increased overtime in both groups compared with that

Table 2. Patients' characteristics of subsidence and non-subsidence group

\begin{tabular}{lccc}
\hline \hline & Subsidence group $(\mathrm{n}=9)$ & Non-subsidence group $(\mathrm{n}=11)$ & $\mathrm{p}$-value* \\
\hline Mean age (years) & 55.3 & 47.9 & 0.104 \\
Sex (male:female) & $8: 1$ & $8: 3$ & 0.051 \\
BMD & $-1.43 \pm 1.0$ & $-1.52 \pm 0.8$ & 0.793 \\
Follow-up period (month) & 68.5 & 85.8 & 0.058 \\
Level of segments & $15(48.4)$ & $16(51.6)$ & 0.847 \\
C3-4 & $2(13.3)$ & $1(6.3)$ & $3(18.8)$ \\
C4-5 & $2(13.3)$ & $7(43.8)$ & \\
C5-6 & $7(46.7)$ & $5(31.3)$ \\
C6-7 & $4(26.7)$ & & \\
\hline
\end{tabular}

BMD: bone mineral density.

${ }^{*}$ Comparison of mean values between the subsidence and non-subsidence group.
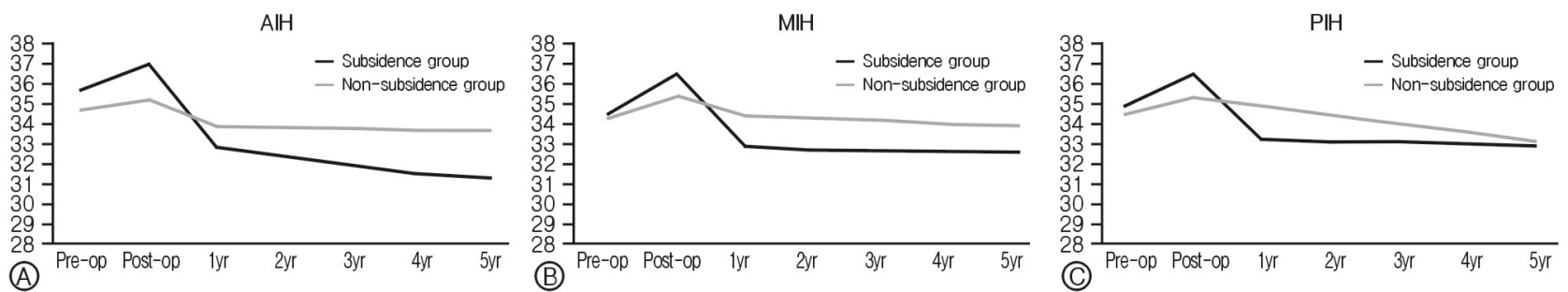

Fig. 2. (A-C) Changes in anterior intervertebral height $(\mathrm{AlH})$, middle intervertebral height $(\mathrm{MHH})$, and posterior intervertebral height $(\mathrm{PIH})$ preoperative, immediate post-operative, 1 year, and 2 years post-operatively, and at the last follow-up between subsidence and non-subsidence group. 
reported post-operatively $(p<0.001)$; the difference bet- ween the two groups was not statistically significant $(p=0.98)$. The fusion rate at the last follow-up was $86.7 \%$ in the subsidence group (13 of 15 segments) and $81.3 \%$ in non-subsidence group (13 of 16 segments) in segmental analysis, and the difference in the fusion rates between the two groups was not statistically significant $(p=0.682$ ) (Table 3). Regarding the non-fusion levels in both groups, there were no worsening of clinical symptoms and radiological findings, additional surgical treatment was not necessary throughout the follow- up period.

\section{Clinical Outcomes}

The overall pre-operative VAS score of neck pain was $3.1 \pm 2.2$ and $3.0 \pm 1.0$ at the last follow-up. At the last follow-up, the score had significantly improved to $3.5 \pm 2.2$ and $4.1 \pm 1.1$ in the subsidence group and non-subsidence group, respectively $(p<0.001)$; and there was no statistical difference between the two groups

Table 3. Radiological outcomes

\begin{tabular}{|c|c|c|c|}
\hline & Subsidence group & Non-subsidence group & $p$-value ${ }^{\ddagger}$ \\
\hline AlH & & & $<0.001^{*}$ \\
\hline Pre-operation & $35.7 \pm 3.1$ & $34.7 \pm 4.6$ & $0.476^{+}$ \\
\hline Post-operation & $37.0 \pm 5.1$ & $34.7 \pm 3.7$ & $0.152^{+}$ \\
\hline 1-year follow-up & $32.9 \pm 4.4$ & $31.9 \pm 1.9$ & $0.499^{+}$ \\
\hline Last follow-up & $31.0 \pm 4.6$ & $33.1 \pm 4.3$ & $0.186^{+}$ \\
\hline$\Delta$ Post-operation - Last follow-up & $6.1 \pm 2.5$ & $1.5 \pm 1.3$ & $<0.001^{+}$ \\
\hline $\mathrm{MlH}$ & & & $<0.001^{*}$ \\
\hline Pre-operation & $34.5 \pm 2.5$ & $34.3 \pm 4.2$ & $0.831^{+}$ \\
\hline Post-operation & $36.5 \pm 4.5$ & $34.4 \pm 3.5$ & $0.155^{+}$ \\
\hline 1-year follow-up & $32.9 \pm 3.9$ & $31.4 \pm 1.7$ & $0.261^{+}$ \\
\hline Last follow-up & $30.6 \pm 4.1$ & $33.0 \pm 3.9$ & $0.110^{+}$ \\
\hline$\Delta$ Post-operation - Last follow-up & $6.0 \pm 2.8$ & $1.5 \pm 1.2$ & $<0.001^{+}$ \\
\hline $\mathrm{PH}$ & & & $<0.004^{*}$ \\
\hline Pre-operation & $34.9 \pm 2.4$ & $34.5 \pm 4.4$ & $0.812^{+}$ \\
\hline Post-operation & $36.5 \pm 4.3$ & $34.3 \pm 3.2$ & $0.112^{+}$ \\
\hline 1-year follow-up & $33.2 \pm 3.8$ & $31.9 \pm 2.1$ & $0.353^{+}$ \\
\hline Last follow-up & $31.9 \pm 3.8$ & $33.1 \pm 4.0$ & $0.399^{+}$ \\
\hline$\Delta$ Post-operation - Last follow-up & $4.6 \pm 3.1$ & $1.2 \pm 1.4$ & $<0.001^{+}$ \\
\hline Cervical sagittal angle & & & $0.003^{*}$ \\
\hline Pre-operation & $-8.2 \pm 18.3$ & $-12.2 \pm 13.0$ & $0.385^{+}$ \\
\hline Post-operation & $-10.5 \pm 10.2$ & $-14.6 \pm 7.9$ & $0.094^{+}$ \\
\hline 1-year follow-up & $-8.1 \pm 13.3$ & $-12.8 \pm 7.4$ & $0.887^{+}$ \\
\hline Last follow-up & $-6.7 \pm 11.9$ & $-12.2 \pm 6.4$ & $0.884^{+}$ \\
\hline$\Delta$ Last follow-up - Post-operation & $3.8 \pm 9.8$ & $2.4 \pm 7.8$ & $0.098^{+}$ \\
\hline Segmental angle & & & $0.154^{*}$ \\
\hline Pre-operation & $-1.7 \pm 7.3$ & $-2.5 \pm 6.0$ & $0.190^{+}$ \\
\hline Post-operation & $-0.4 \pm 5.9$ & $-3.8 \pm 4.7$ & $0.737^{+}$ \\
\hline 1-year follow-up & $0.9 \pm 7.4$ & $-2.6 \pm 5.1$ & $0.668^{+}$ \\
\hline Last follow-up & $1.9 \pm 8.0$ & $-2.1 \pm 5.0$ & $0.301^{+}$ \\
\hline$\Delta$ Last follow-up-Post-operation & $2.3 \pm 8.5$ & $1.7 \pm 5.2$ & $0.119^{+}$ \\
\hline \multicolumn{4}{|l|}{ Fusion } \\
\hline Last follow-up & $13(86.7)$ & $13(81.3)$ & 0.682 \\
\hline
\end{tabular}

The data is presented as mean \pm standard deviation or number (\%).

$\mathrm{AlH}$ : anterior intervertebral height; $\mathrm{MH}$ : middle intervertebral height; $\mathrm{PIH}$ : posterior intervertebral height.

${ }^{*}$ Comparison of mean values between postoperation and last follow-up. ${ }^{+}$Comparison of mean values between the subsidence and non-subsidence groups. ${ }^{\dagger}$ Paired t-test was used for analysis. 
Table 4. Clinical outcomes

\begin{tabular}{|c|c|c|c|}
\hline & Subsidence group & Non-subsidence group & $p_{\text {-value }}^{\ddagger}$ \\
\hline VAS_neck & & & $<0.001^{*}$ \\
\hline Pre-operation & $6.0 \pm 2.6$ & $6.9 \pm 1.5$ & $0.226^{+}$ \\
\hline Last follow-up & $3.1 \pm 2.2$ & $3.0 \pm 1.0$ & $0.831^{+}$ \\
\hline$\Delta$ Pre-operation-Last follow-up & $3.5 \pm 2.2$ & $4.1 \pm 1.1$ & $0.441^{+}$ \\
\hline VAS_arm & & & $<0.001^{*}$ \\
\hline Pre-operation & $6.8 \pm 1.1$ & $6.8 \pm 1.5$ & $0.916^{+}$ \\
\hline Last follow up & $3.9 \pm 1.8$ & $3.3 \pm 1.8$ & $0.350^{+}$ \\
\hline$\Delta$ Pre-operation - Last follow-up & $3.3 \pm 1.7$ & $3.6 \pm 1.4$ & $0.632^{+}$ \\
\hline $\mathrm{NDI}$ & & & $<0.001^{*}$ \\
\hline Pre-operation & $19.3 \pm 9.8$ & $22.4 \pm 11.6$ & $0.440^{+}$ \\
\hline Last follow-up & $4.5 \pm 3.4$ & $6.3 \pm 5.9$ & $0.336^{+}$ \\
\hline$\Delta$ Pre-operation - Last follow-up & $13.8 \pm 10.1$ & $15.7 \pm 14.7$ & $0.706^{+}$ \\
\hline
\end{tabular}

VAS: visual analogue scale; NDI: neck disability index.

${ }^{*}$ Comparison of mean values between the post-operation and last follow-up. ${ }^{+}$Comparison of mean values between the subsidence and nonsubsidence group. ${ }^{\ddagger}$ Paired t-test was used for analysis.

$(p=0.441)$. The overall pre-operative VAS score of arm pain was $3.9 \pm 1.8$ and $3.3 \pm 1.8$ at the last follow-up. At the last follow-up, it had significantly improved to $3.3 \pm 1.7$ and $3.6 \pm 1.4$ in the subsidence group and non-subsidence group, respectively $(p<0.001)$; and there was no statistical difference between the two groups $(p=0.632)$. Furthermore, the NDI score had improved over time during the follow-up period in both groups $(p<0.001)$, and the difference was not statistically significant $(p=0.706)$ (Table 4). No patients reported worsening pain or an increase in the NDI score during the follow-up period.

\section{DISCUSSION}

ACDF with plate fixation has been considered the "gold standard" for safe and solid cenvical interbody fusion in the treatment of degenerative cenvical disease ${ }^{15,25)}$. Anterior plate fixation improves cervical spine stability, enhances the fusion rate, and maintains the intervertebral height and cenvical physiological curvature, thus reducing the complications of post-operative graft collapse and loss of physiological curvature ${ }^{12)}$. In addition, various materials have been developed and used for interbody grafts with the ACDF, in order to avoid morbidity associated with autologous bone grafts. PEEK material cages have been developed to achieve immediate stability and successful bone fusion ${ }^{3)}$. With the development of synthetic cages and boneinductive substances, questions have arisen about the need for additional anterior plate fixation which can lead to complications such as material failure, dysphagia, and $A S D^{13,14,17,19)}$. Recently, several studies suggested that stand-alone ACDF is a safe and effective modality for cervical degenerative disease $e^{4,16,18,20,24)}$. However, it remains controversial because the outcome of the standalone ACDF of these reports included only two-year or much lower follow-up periods. In this study, we revealed a radiological and clinical longterm outcome with a follow-up period of more than 5 years after stand-alone ACDF.

The main consideration relating to stand-alone ACDF is subsidence. The generally accepted hypothesis regarding subsidence after standalone ACDF is that, since there is no plate to support axial loading, the intervertebral space collapses as the implant penetrates the vertebral body. Kim et al. ${ }^{10)}$ reported that the subsidence occurred $58.6 \%$ after performing stand-alone ACDF with an average 5-year follow-up. They suggested that the subsidence was progressed over time continuously until the last follow-up period. In addition, the VAS score of the patients' neck and arm increased, the patient's satisfaction was assessed using Odom's criteria, and 64.6\% of patients responded as unsatisfactory at the last follow-up. However, no statistical association was found between subsidence and clinical outcome. In our study, although the $48.4 \%$ subsidence occurred, neck and arm pain were relieved, and NDI scores improved at the last follow-up $(p<0.001)$. None of the patients experienced worsening pain or neurologic symptoms after surgery, and no clinically negative outcomes associated with subsidence were reported. In addition, the decrease of intervertebral height mostly occurred within one-year after surgery, after that, we could find the tendency of decrease of intervertebral height was negligible until the last follow-up in non-subsidence group (Fig. 2). Similarly to our results, many previous reports revealed that the subsidence was not significantly associated with clinical outcome, and mostly occurred within one-year after surgery and then be stabled ${ }^{7-9,11)}$. If the subsidence occurs, it may be assumed that the foraminal height would also decrease, affecting clinical outcomes. However, the VAS score of arm pain in subsidence group was significantly improved $(p<0.001)$ in our study. We suggest that if foramen decompression is adequately and sufficiently performed during surgery, subsidence does not affect 
the clinical outcome.

The fusion rate reached $82.8 \%$ with good stability in our study. With the development of synthetic cages and bone-inductive substances, the use of anterior plating in ACDF did not seems to provide obviously high fusion rates. Meanwhile, Wu et al. ${ }^{23)}$ reported that rigid anterior plating may act as a shield for the mechanical load, which is very important for fusion. It has been hypothesized that during the process of bone fusion and remodeling, cage subsidence could be the consequence of cage settlement, contributing to mechanical loading of the bone graft inside the cage, thus promoting fusion ${ }^{2,22)}$. Many reports have revealed that stand-alone ACDF achieved a successful fusion rate higher than 90\%, 18,20 ). Although not statistically significant, our study showed higher fusion rates in the subsidence group than in the non-subsidence group (Table 3). Regrading cervical stability, although the changes in CSA and SA values from the post-operative to the last follow-up values were larger in subsidence group than in the non-subsidence group, the difference between the two groups was not statistically significant. Considering that the pre-operative CSA and SA values in the sub- sidence group were larger than those in the non-subsidence group, it can be assumed that the pre-operative CSA and $S A$ values may affect the amount of change in the post-operative CSA and SA values. Consequently, stand-alone ACDF does not seem to be the only factor in the deterioration of SA and CSA.

Except for subsidence, no surgery-related complications occurred. In addition, although subsidence had occurred in $48.4 \%$ of the patients, their VAS or NDI scores had improved and additional surgical treatment was not necessary throughout the follow-up period. In addition, until now, most previous reports have failed to explain the subsidence as a factor predicting low fusion rates, unsatisfactory clinical outcomes, and kyphotic change after surgery ${ }^{7,8)}$. Subsidence is an inevitable consequence of stand-alone ACDF; we suggest that proper subsidence with the sinking of cages into the vertebral bodies may contribute to solid fusion and does not adversely affecting clinical outcomes and cervical alignment.

This retrospective study had some limitations. This study comprised a small number of patients, and there was no control group to compare the radiological and clinical outcomes. Moreover, the predictive factors for subsidence and kyphotic change were not determined. Further randomized prospective studies are needed to determine the efficacy and toxicity associated with stand-alone ACDF surgery.

\section{CONCLUSION}

As a result of a long-term follow-up study after stand-alone ACDF, subsidence occurs to some extent. Still, it does not appear to significantly impact radiological and clinical outcomes if the clinician performs sufficient decompression of foramen during surgery. Subsidence seems to have a positive influence on the fusion rate. Overall, stand-alone ACDF appears to be an acceptable surgical option for treating degenerative cenvical disease.

\section{CONFLICTS OF INTEREST}

No potential conflict of interest relevant to this article was reported.

\section{REFERENCES}

1. Barsa P, Suchomel P: Factors affecting sagittal malalignment due to cage subsidence in standalone cage assisted anterior cervical fusion. Eur Spine J 16:1395-400, 2007

2. Bartels RH, Donk RD, Feuth T: Subsidence of stand-alone cervical carbon fiber cages. Neurosurgery 58:502-508, 2006

3. Cho DY, Liau WR, Lee WY, Liu JT, Chiu CL, Sheu PC: Preliminary experience using a polyetheretherketone (PEEK) cage in the treatment of cervical disc disease. Neurosurgery 51: 1343-1350, 2002

4. Fujibayashi S, Neo M, Nakamura T: Stand-alone interbody cage versus anterior cervical plate for treatment of cervical disc herniation: sequential changes in cage subsidence. J Clin Neurosci 15:1017-1022, 2008

5. Gercek E, Arlet V, Delisle J, Marchesi D: Subsidence of standalone cervical cages in anterior interbody fusion: warning. Eur Spine J 12:513-516, 2003

6. Haden N, Latimer M, Seeley HM, Laing RJ: Loss of intervertebral disc height after anterior cervical discectomy. Br J Neurosurg 19:469-474, 2005

7. Joo YH, Lee JW, Kwon KY, Rhee JJ, Lee HK: Comparison of fusion with cage alone and plate instrumentation in twolevel cervical degenerative disease. J Korean Neurosurg Soc 48: 342-346, 2010

8. Karikari IO, Jain D, Owens TR, Gottfried O, Hodges TR, Nimjee SM, et al.: Impact of subsidence on clinical outcomes and radiographic fusion rates in anterior cervical discectomy and fusion: a systematic review. J Spinal Disord Tech 27:1-10, 2014

9. Kast E, Derakhshani S, Bothmann M, Oberle J: Subsidence after anterior cervical inter-body fusion. A randomized prospective clinical trial. Neurosurg Rev 32:207-214, 2009

10. Kim WB, Hyun SJ, Choi H, Kim KJ, Jahng TA, Kim HJ: Longterm follow-up results of anterior cervical inter-body fusion with stand-alone cages. J Korean Neurosurg Soc 59:385-391, 2016

11. Lee CH, Hyun SJ, Kim MJ, Yeom JS, Kim WH, Kim KJ, et al.: Comparative analysis of 3 different construct systems for single-level anterior cervical discectomy and fusion: stand-alone cage, iliac graft plus plate augmentation, and cage plus plating. J Spinal Disord Tech 26:112-118, 2013

12. Li J, Zheng Q, Guo X, Zeng X, Zou Z, Liu Y, et al.: Anterior surgical options for the treatment of cervical spondylotic myelopathy in a long-term follow-up study. Arch Orthop Trauma Surg 133:745-751, 2013

13. Marawar S, Girardi FP, Sama AA, Ma Y, Gaber-Baylis LK, Besculides MC, et al.: National trends in anterior cervical fusion procedures. Spine (Phila Pa 1976) 35:1454-1459, 2010

14. Moreland DB, Asch HL, Clabeaux DE, Castiglia GJ, Czajka GA, Lewis PJ, et al.: Anterior cervical discectomy and fusion with implantable titanium cage: initial impressions, patient outcomes and comparison to fusion with allograft. Spine J 4:184191, 2004

15. Papacci F, Rigante L, Fernandez E, Meglio M, Montano N: Anterior cervical discectomy and interbody fusion with porous 
tantalum implant. Results in a series with long-term follow-up. J Clin Neurosci 33:159-162, 2016

16. Pereira EA, Chari A, Hempenstall J, Leach JC, Chandran H, Cadoux-Hudson TA: Anterior cervical discectomy plus intervertebral polyetheretherketone cage fusion over three and four levels without plating is safe and effective long-term. J Clin Neurosci 20:1250-1255, 2013

17. Schröder J, Grosse-Dresselhaus F, Schul C, Wassmann H: PMMA versus titanium cage after anterior cervical discectomy - a prospective randomized trial. Zentralbl Neurochir 68:2-7, 2007

18. Shiban E, Gapon K, Wostrack M, Meyer B, Lehmberg J: Clini$\mathrm{cal}$ and radiological outcome after anterior cervical discectomy and fusion with stand-alone empty polyetheretherketone (PEEK) cages. Acta Neurochir (Wien) 158:349-355, 2016

19. Sugawara T, Itoh Y, Hirano Y, Higashiyama N, Mizoi K: Long term outcome and adjacent disc degeneration after anterior cervical discectomy and fusion with titanium cylindrical cages. Acta Neurochir (Wien) 151:303-309, 2009

20. Tabaraee E, Ahn J, Bohl DD, Collins MJ, Massel DH, Aboushaala $\mathrm{K}$, et al.: Comparison of surgical outcomes, narcotics utilization, and costs after an anterior cervical discectomy and fusion: Stand-alone cage versus anterior plating. Clin Spine Surg 30:E1201-E1205, 2017
21. Thomé C, Krauss JK, Zevgaridis D: A prospective clinical comparison of rectangular titanium cages and iliac crest autografts in anterior cervical discectomy and fusion. Neurosurg Rev 27: 34-41, 2004

22. Tomé-Bermejo F, Morales-Valencia JA, Moreno-Pérez J, Marfil-Pérez J, Díaz-Dominguez E, Piñera AR, et al.: Degenerative cervical disc disease: Long-term changes in sagittal alignment and their clinical implications after cervical inter- body fusion cage subsidence: A prospective study with standalone lordotic tantalum cages. Clin Spine Surg 30:E648-E655, 2017

23. Wu WJ, Jiang LS, Liang Y, Dai LY: Cage subsidence does not, but cervical lordosis improvement does affect the longterm results of anterior cervical fusion with stand-alone cage for degenerative cervical disc disease: a retrospective study. Eur Spine J 21:1374-1382, 2012

24. Yamagata T, Takami T, Uda T, Ikeda H, Nagata T, Sakamoto $\mathrm{S}$, et al.: Outcomes of contemporary use of rectangular titanium stand-alone cages in anterior cervical discectomy and fusion: cage subsidence and cervical alignment. J Clin Neurosci 19: 1673-1678, 2012

25. Yue WM, Brodner W, Highland TR: Long-term results after anterior cervical discectomy and fusion with allograft and plating: a 5- to 11-year radiologic and clinical follow-up study. Spine (Phila Pa 1976) 30:2138-2144, 2005 